\title{
O PROJETO ANA TERESA: O CAMINHO PARA DESINSTITUCIONALIZAÇÃO DO DOENTE MENTAL?
}

\author{
THE ANA TERESA PROJECT: A WAY TO GET THE MENTAL \\ ILL OUT OF INSTITUTION \\ EL PROYECTO ANA TERESA ¿EL CAMINO PARA MODIFICAR LA \\ TRAYECTORIA DE ENFERMOS MENTALES EN \\ INSTITUTOS DE CONFINAMIENTO?
}

Eliani Costa ${ }^{1}$

Miriam Süsskind Borenstein ${ }^{2}$

\begin{abstract}
RESUMO: Trata-se de um projeto que apresenta uma nova abordagem no tratamento destinado à pacientes psiquiátricos crônicos e asilares, cujo objetivo principal è oferecer a estes, uma condição de vida que permita deixarem de serem pacientes despersonalizados, excluidos e estigmatizados, para tornarem-se cidadăos com plenas potencialidades.
\end{abstract}

PALAVRAS-CHAVE: hospital psiquiátrico, doente mental, Enfermagem.

\section{INTRODUZINDO A IDÉIA}

A partir dos anos setenta, se instaurou no Brasil, um movimento de crítica às politicas oficiais de saúde no campo psiquiátrico. Tal movimento surgiu em decorrência das críticas e denúncias dos trabalhadores de saúde mental e de outros segmentos da sociedade civil, sobre a violência e o abandono, ao qual os pacientes de hospitais psiquiátricos estavam sujeitos (Aguiar, 1995, p. 152). Este năo era um movimento isolado, pois, desde o final da Segunda Guerra Mundial, já haviam se iniciado na Europa e nos Estados Unidos, novas formas de tratamento a saber: na Inglaterra, as comunidades terapêuticas, psicoterapia institucional e a psiquiatria de setor; no Estados Unidos a psiquiatria comunitária, e mais tardiamente a Itália, com a psiquiatria democrática, com intuito de melhorar o tratamento psiquiátrico destinado ao doente, tornando-o mais terapêutico e humano (Aguiar, 1995, p. 147).

No Brasil, as condiçōes dos macro hospitais psiquiátricos estatais nesta época se caracterizavam por serem grandes depósitos, e segundo Moffat (1995, p. 20), "eram lugares fechados e distantes, com aspecto muito sujo, engordurado, escuro, povoado de objetos velhos e apresentavam um cheiro caracteristico de mistura de graxa rançosa com odores corporais, em decorrência da ausência de ventilação".

Havia portanto, uma necessidade premente de alternativas ao modelo manicomial, criando serviços extra-hospitalares, com o propósito de atender a uma demanda da comunidade, enquanto o hospital na sua estrutura fisica, administrativa e técnica, deveria sofrer mudanças de peso para adequação às novas filosofias de tratamento.

'Enfa. do Instituto de Psiquiatria Santa Catarina (IPQ) - Sāo José - S.C. - Coord. da Unidade Ana Teresa (São Pedro de Alcantâra - S.C). Enfermeira Especialista em Enfermagem do Trabalho.

${ }^{2}$ Professora Adjunta III do Departamento de Enfermagem da UFSC - Doutoranda em Filosofia da Enfermagem - UFSC. 
É neste contexto que os trabalhadores de saúde começaram a se articular em diversos locais significativos, enquanto espaço de mobilização e debate, acerca da absurda realidade dos manicômios. Os trabalhadores de saúde mental e vários segmentos da sociedade se colocaram contra esta realidade, exigindo uma politica de saúde mental mais ampla no pais. Dessa forma os trabalhadores se articularam e se estruturaram em vários núcleos regionais, buscando estabelecer um diálogo com a sociedade sobre o real significado dos manicômios (Aguiar, 1995, p. 151).

É na década de 80 portanto, que se enraizou no Brasil, este movimento e desde então, vem se consolidando em todo o pais, uma nova percepção do papel das práticas e das instituições psiquiátricas, que se distancia das experiências levadas a cabo até os ano 70. Ȧ este processo de modernização das práticas psiquiátricas e criação de novas alternativas de tratamento para o doente mental, denominamos de "Reforma Psiquiátrica Brasileira" (Bezerra Júnior, 1994).

Em Santa Catarina, o Hospital Colônia Santana (HCS), inaugurado em 1941, foi construido para ser um modelo no tratamento de doenças mentais no Estado, porém apesar dos esforços, tornou-se um depósito de doentes, chegando a abrigar na década de 70,1600 pacientes. Neste periodo, se tem lembranças de acủmulo de pacientes, "leitos - chão", no qual dois ou três pacientes dormiam na mesma cama, a situação se caracterizava por miséria, promiscuidade e violência.

O hospital havia polarizado para si, toda a problemática de assistência mental do Estado, e com isso concentrou encargos e atribuições múltiplas que extrapolaram sua função hospitalar. Como conseqüência, passou a assumir uma assistência custodial que se tornou predominante em relação aos outros tipos de recursos terapêuticos. Evidentemente que esta confusão de funções e a precária assistência oferecida, culminou com a superlotação e no agrupamento desordenado de pacientes com diagnósticos variados, e com necessidades humanas básicas distintas. Deparamo-nos então, com uma super população de doentes crônicos, sem vínculo familiares, sem referência previdênciária e institucionalizados. A maioria destes pacientes permaneceram num estágio de cronicidade estável não evoluindo a um estágio final de deterioração. Seus sintomas psicóticos não eram tão severos e poderiam residir fora do hospital. No entanto o ócio em que a instituição submeteu-os, levou a um gradual afastamento de suas atividades e costumes, com um empobrecimento de suas funções.

Segundo alguns autores, o ócio leva a perda da dimensão temporal do naciente, favorecendo a certos estados patológicos. A não realização de atividades concretas e espontâneas faz com que os doentes adotem atividades substitutas, estereotipadas e hábitos mórbidos, que os tornam incapazes de viverem em sociedade. Essa perda de ação, às vezes se mostra através da aceitação passiva dos estimulos ambientais, demonstrando uma obediência automática às ordens, mesmo sem compreensão de seu significado.

No adoecer do doente mental existe uma perda do contato com o mundo real. Talvez esta perda do contato, exista na mesma proporção em que o mundo que o cerca corta o contato com ele. O grupo familiar o rejeita e a sociedade the teme. A doença lhe trará um estigma e o marcará para o resto da sua vida, como pessoa indigna de crédito e de novas oportunidades.

Com pacientes com estas caracteristicas, e problemas de toda ordem, o HCS com uma capacidade total de 1.000 leitos, chegou à década de 80 , à internar 1.200 pacientes. Estes eram provenientes dos mais diversos locais do Estado e fora deste. Quanto ao perfil dos pacientes internados, em sua grande maioria, eram oriundos do meio rural, desempenhavam atividades primárias (agricultores) antes da internação, de baixo nivel sócio-econômico e cultural, com instabilidade na vida familiar, sobrevivendo em precárias condições. 
Quanto aos familiares, estes viviam longe do hospital, em cidades do interior, possuiam baixa renda, pouca instrução, apresentavam medo e preconceito em relação à doença mental.

A proporção alarmante de pacientes crônicos e institucionalizados, num total de 863 pacientes, em relação aos quase 300 com razoável prognóstico e diagnóstico, fez com que o grupo de técnicos procurasse desenvolver trabalhos alternativos que viessem atender a esta populaçăo de crônicos. Uma das alternativas, foi um trabalho de tentativa de retorno ao convívio familiar, em que foram realizadas inúmeras viagens de ônibus para o Oeste do Estado, de onde a maioria era procedente. As viagens tinham como objetivo além do retorno dos pacientes aos seus lares, orientar as familias de como tratar seus doentes e buscar junto ao municipio, apoio para a permanência destes em suas casas. Desenvolveu-se também um programa de triagem melhorada, na tentativa de envolver os familiares na internação do paciente, devolvendo-o ao convivio familiar e a sociedade, o mais precoce possivel .

Juntamente com estas medidas, o grupo de técnicos (médicos, enfermeiras, assistentes sociais e outros do HCS), resolveu repensar em um novo tipo de vida e tratamento para os pacientes que permaneciam institucionalizados. Estimulados pela reforma psiquiátrica que se instaurava no país, viram a possibilidade de criar, a exemplo de Porto Alegre (RS), um projeto de reabilitaçăo do doente mental através de trabalhos agricolas.

A idéia surgiu a partir de uma visita realizada ao Hospital Psiquiátrico São Pedro (HPSP), em Porto Alegre - RS, em 1984. Este também, um macro hospital psiquiátrico estatal, com características e problemática semelhantes ao HCS. O HPSP, havia criado um Centro Agrícola de Reabilitação para os pacientes crônicos da instituição, em Itapoä (Viamão - RS), município localizado a $60 \mathrm{Km}$ da capital. Do relato desta visita, realizada por alguns técnicos do HCS, representados pelo Administrador, por uma enfermeira, e por uma assistente social, surgiu a idéia da criação de um Centro de Reabilitação Agrícola (CRA), aproveitando o espaço físico ocioso e abandonado do Hospital Colônia Santa Teresa (HCST), especializado em hanseniase e distante somente a $7 \mathrm{Km}$ do $\mathrm{HCS}$.

Foi entăo formada uma comissão com alguns técnicos do HCS e direçăo do HCST, para elaborarem o projeto e apresentarem à Secretaria de Saúde do Estado. Entretanto, devido as dificuldades administrativas, o mesmo só foi concluido e aprovado, em 1986. O referido projeto recebeu inicialmente o nome de Centro de Reabilitaçăo Agricola (CRA) e teve por base o projeto original de Itapoă - RS, que buscava a reabilitação e reinserção do doente mental crônico à sociedade e à sua familia, através da recuperação de habilidades perdidas nos longos anos de internaçăo na instituição. Posteriormente o projeto passou a chamar-se "Projeto Ana Teresa", em homenagem a junção das duas Instituiçőes (HCS e HCST), sendo depois designada como "Unidade Ana Teresa" (UAT) e progressivamente adaptada à ralidade catarinense, mantendo entretanto os pressupostos originais, ou seja, de reinserção do paciente psiquátrico crônico à sociedade.

\section{OPROJETO ANA TERESA}

\section{ASPECTOS NORTEADORES DO PROJETO Cinco foram os aspectos que nortearam a criaçăo do Projeto Ana Teresa:}

Perfil dos pacientes internados no HCS, em 1984: a partir do estudo realizado no HCS em 1984, com o objetivo da setorizaçăo, foi observado que: $55,7 \%$ dos pacientes foram caracterizados como crônicos (com início da doença há mais de cinco anos e com maior tempo de permanência na instituição do que em casa); 19,3\% como asilares (sem vínculo e ou contato familiar há mais de três anos) e os demais $25 \%$, constituíram-se por serem: agudos, dependentes quimicos e deficientes mentais. 
A história do HCS e a super população: o HCS, hoje denominado Instituto de Psiquiatria do Estado de Santa Catarina (IPQ), situado em São José - SC, è um macro hospital psiquiátrico estatal, que tem na sua história, atendido a uma clientela previdenciária e carente de recursos, sendo que estes últimos, geralmente ocuparam o maior número dos leitos. Sua capacidade era de 1.000 leitos, entretanto com uma média de ocupação de $120 \%$.

História do HCST X Ociosidade da área física: o HCST está localizado no municipio de São Pedro de Alcântara - SC, 30 km de Florianópolis e a 7 km do HCS, é também um órgão da SES, subordinado à FHSC. Era um macro hospital, que vinha prestando assistência à pacientes com doença de Hansen desde 1939. Foi planejado e organizado como uma vila, com a devida organização politica e social, sendo dividida em duas partes: uma destinada aos pacientes, e a outra, aos funcionários e seus familiares. Com os avanços na terapêutica da hanseniase, várias modificações foram adotadas em relação ao tratamento dos doentes com este diagnóstico. Na época e atualmente, já năo se exige o confinamento hospitalar e por este motivo, gradativamente os pavilhões foram sendo desocupados assim como o restante da área física. Inicialmente o HCST contava com uma população de 540 pacientes, distribuidos em 14 pavilhões e 28 casas conjugadas, sendo que em 1984, contava com um total de 97 pacientes, distribuidos em 3 pavilhőes e 8 casas. OHCST dispunha de todos os serviços necessários para a manutenção dos mesmos, tais como lavanderia, refeitório, área de lazer, etc.

A ocupação de leprosário por doentes mentais não é um fato recente. Em "História da Loucura", Foucault (1995), relata que as instituições asilares para "loucos", foram herança da desativação dos inúmeros leprosários existentes na Europa, até o século XVII.

Média de Permanência $X$ Custos : outro fator relacionado era a média de permanência no hospital, e consequentemente, a capacidade de internaçăo e seu custo. No HCS, os pacientes crônicos e asilares tinham uma permanência prolongada, quando não definitiva na instituição, o que provocava entre outras coisas, o encarecimento assistencial. Uma forma de minimizar os gastos era a reabilitação, que estimulava o individuo para a independência financeira. Em 1984, $75 \%$ dos pacientes do HCS, eram considerados casos sociais, o que muito contribuia para aumentar a média de permanência e, consequentemente, os gastos institucionais.

Necessidade de Implementação da Investigação (Pesquisa): o Hospital, afim de poder restaurar a saúde da população, prevenir a doença e reabilitar habilidades, além de executar funçőes educativas, deve ser uma unidade dinâmica no seio da sociedade e manter-se continuamente atualizado, testando e aplicando nova tecnologias de assistência. Só assim obterá melhores resultados em um menor espaço de tempo, esforço e custo operacional. Para atingir estes objetivos, era importante que o hospital implementasse pesquisas ligando todos os campos de sua atividade. Criando o CRA, acreditávamos que este cumpriria esta funçāo, na medida em que se buscava a reabilitação através da educação e reintegração familiar e social.

\section{OBJETIVOS DO PROJETO}

Em relação aos pacientes: através de um processo continuo, coordenado e levado a efeito por uma equipe multidisciplinar, pretendia-se recuperar o doente mental crônico, dentro dos aspectos biológico, psicológico, social e profissional, através da realização de atividades rurais.

Em relação à equipe terapêutica: possibilitar treinamento e aperfeiçoamento constante da equipe multidisciplinar e de enfermagem que as capacitasse para este tipo de trabalho, e de outros profissionais que buscassem o hospital.

Em relação à Instituição: reduzir o nủmero de pacientes crônicos no HCS, implementando uma nova proposta de modelo de assistência psiquiátrica aos pacientes crônicos asilares, e oferecendo um maior número de recursos terapêuticos aos pacientes agudos (psicóticos, dependentes quimicos e deficientes mentais). 


\section{REQUISITOS PARA TRIAGEM DOS PACIENTES}

A fim de selecionar os pacientes do HCS, para participare do CRA, foram estabelecidos os seguintes critérios:

Pacientes com patologia esquizofrênica prioritariamente: as demais psicoses funcionais não foram excluidas definitivamente entretanto com a proposta de um hospital aberto, os distúrbios de conduta, história pregressa de uso de álcool e/ou outras drogas ficaram excluidos totalmente, bem como, os pacientes com acentuados riscos de agressão, fuga e suicidio. Os pacientes deficientes mentais severos foram excluidos devido a pouca capacidade destes para acompanharem as atividades propostas.

Pacientes do sexo masculino: considerando que o maior número de pacientes crônicos e asilares eram do sexo masculino, o CRA foi proposto inicialmente para estes.

Oriundo do meio rural: os pacientes em sua grande maioria, eram provenientes do meio rural e como tal, acreditava-se que esta vinculaçăo ao meio de origem, era um fator fundamental para sua recuperação, pois haveria um forte envolvimento com suas raizes (terraagricultura).

Sem vínculo previdenciário: Quando do estudo realizado para traçar o perfil da populaçăo do HCS em 1984, observou-se que $60 \%$ dos pacientes crônicos eram classificados como casos sociais (pessoas carentes de recursos financeiros e assistenciais) e sobre estes, deveria incidir o CRA, pois a permanência destes pacientes no hospital, acarretava um alto custo financeiro.

Com início da doença há mais de cinco anos e permanência na Instituição mais de $50 \%$ de sua vida: este foi um dos requisitos mais importantes, tendo em vista que o projeto foi idealizado justamente à esta demanda (crônicos institucionalizados).

Idade entre $\mathbf{2 5}$ a $\mathbf{5 0}$ anos: a idade minima estabelecida era de 25 anos e a idade máxima de 50 anos. Entretanto poderia haver uma flexibilidade para a idade minima (que não fosse inferior a 18 anos, pois o CRA era destinado à adultos), como para a máxima, desde que a admissão destes pacientes não viesse Ihes trazer prejuizos físicos, e que sua transferência representasse uma tentativa real de reabilitação.

Com vinculo familiar reduzido ou inexistente: embora cientes que o vinculo familiar era um elemento determinante na evolução do tratamento e no prognóstico dos pacientes, o projeto previu o incentivo de vinculos com terceiros, pois a maioria dos pacientes crônicos, possuiam reduzidos laços familiares ou inexistentes.

Com reduzida ou nenhuma medicação psiquiátrica: considerando o tipo de trabalho que seria desenvolvido, o ideal era que os pacientes utilizassem pouca ou nenhuma medicação psiquiátrica. Viu-se entretanto que os casos poderiam ser avaliados individualmente.

Com condições clínicas compativeis com a tarefa agricola: como as atividades terapêuticas previstas eram basicamente a laborterapia agropastoril, deveriam ser excluidos pacientes com patologias incapacitantes para o trabalho como: aqueles portadores de deformidades fisicas e/ou de doenças crônicos degenerativas. Foi previsto também, que os pacientes que apresentassem intercorrências clínicas e/ou psiquiátricas graves, retornariam ao HCS, permanecendo neste, até a remissão total dos sintomas.

Após terem sido estabelecidos os aspectos norteadores e os objetivos do projeto, faremos a seguir, de forma sintética a descriçăo do que foram estes 10 anos da Unidade Ana Teresa (UAT). 
A UNIDADE ANA TERESA - 10 ANOS - (1987- 1997)

\section{A IMPLANTAÇÃO DO PROJETO}

Após a aprovação do projeto, foi escolhida pela Direção do HCS, (doravante denominado IPQ), uma das enfermeiras que participou deste, desde seu início. Esta enfermeira, passou a coordenar o processo das reformas, a preparação do espaço físico, a seleção dos pacientes a serem transferidos, bem como a seleção e treinamento dos funcionários que fariam parte da equipe.

Toda a área destinada ao projeto, encontrava-se em total abandono e envolta por mato. Foi então formada uma equipe com os primeiros pacientes selecionados. Diariamente este grupo era levado ao HCST, para preparar a área juntamente com um atendente, orientados pela enfermeira. Este grupo realizou a capina, organizou as reformas, bem como foi responsável pela organização e preparo de todo o ambiente e material.

O primeiro grupo de 14 pacientes, foi transferido em 02 de fevereiro de 1987, dia em que foram realizadas as comemorações de inauguraçăo da UAT. A inauguração contou com a presença das autoridades estaduais e institucionais comprometidas com o trabalho.

\section{A DINÂMICA DE TRANSFERÊNCIA}

Na dinâmica de transferência dos primeiros pacientes, foi observado que os critérios de triagem năo seriam facilmente obedecidos, uma vez que já no primeiro grupo, encontramos uma mistura de condições que os tornariam inelegiveis, se criteriosamente observados. Neste primeiro grupo, foram transferidos pacientes com idade superior a 50 anos e pacientes com problemas fisicos, entretanto não incapacitantes para a atividade agricola. Pacientes deficientes mentais, também não foram completamente excluidos, desde que moderados e com condições compativeis para o trabalho a ser realizado.

O perfil dos pacientes do primeiro grupo se caracterizou por: em relação ao diagnóstico médico, três (3) eram deficientes mentais, dois (2) eram epiléticos e os demais (9), eram esquizofrênicos. Em relação a prodedência, três (3) eram procedentes do meio urbano, nove (9) do meio rural e um (1) de região desconhecida. Em relação ao tempo de permanência, todos estavam há mais de 10 anos internados. Em relação ao vínculo familiar e previdenciário, quatro (4) dos pacientes possuiam familia entretanto há mais de 3 anos não recebiam visita, dois (1) possiam familia, sem visitas e nove (9), não possuiam família. Dois (2) pacientes eram aposentados sendo que um deles, a familia era quem ficava com seu beneficio, fato que foi modificado posteriormente, e os demais não possuiam seguro saúde, aposentadoria ou qualquer outro tipo de recurso financeiro. Em relação ao uso de medicamentos, todos faziam uso de duas (2) ou mais medicações psiquiátricas e em relaçăo às condiçōes físicas, todos possuiam condiçōes compativeis para o trabalho agricola, e eram do sexo masculino. Um (1) dos pacientes, encontrava-se sob júdice.

\section{A DISTRIBUIÇÃO DOS PACIENTES}

Os pacientes foram distribuidos em 7 quartos de um pavilhäo, sendo 2 em cada quarto. Estes, possuiam duas camas, um guarda-roupa com divisórias individuais e cadeados. Os pacientes tiveram a oportunidade de escolher seus quartos, bem como, o companheiro com quem iriam dividir o mesmo. Dos 5 pavilhōes destinados à psiquiatria, somente 3 foram reformados, e gradativamente foram sendo transferidos 36 pacientes, que ocuparam 2 pavilhões de 9 quartos cada um. Um dos pavilhőes, foi destinado às atividade técnicas e administrativas do projeto, sua reforma foi feita baseada nesta finalidade. Os quartos foram respectivamente 
transformados em um posto de enfermagem, um consultório médico, uma rouparia, uma sala para terapia ocupacional, uma sala para enfermeira, um banheiro para funcionários e finalmente, um dos quartos, foi destinado para os pacientes que eventualmente apresentassem intercorrências psiquiátricas ou problemas clinicos moderados. Este pavilhăo situado no meio dos outros cinco, recebeu o nome de pavilhão central.

\section{A RECEPÇĀO E CONVIVIO DOS PACIENTES NO HOSPITAL COLÓNIA SANTA TERESA.}

Como toda mudança gera inicialmente resistência, no novo convivio, houve inicialmente medo de ambos os lados. Os pacientes da psiquiatria rejeitavam e temiam a "lepra" e os pacientes da hanseniase temiam os pacientes psiquiátricos. Iniciamos o trabalho de esclarecimento de ambos os lados e os pacientes da psiquiatria é que iniciaram a "quebra do gelo", iniciando as conversas com os pacientes do HCST.

O projeto previa a construção de um muro para separar as duas unidades. A experiência mostrou que o muro era somente uma concepção mental dos técnicos, pois os pacientes mostraram que o convivio era possivel, o que aconteceu de forma natural, e nos fez abandonar logo a idéia. Os pacientes passaram a trocar favores e trabalhos entre si, como por exemplo, uma das pacientes egressas do HCST, lavava e passava a roupa de alguns pacientes da UAT. Os pacientes da UAT, capinavam para os pacientes da Unidade de hanseniase.

Houve inicialmente um rechaço por parte dos funcionários do HCST. Estes verbalizavam um sentimento de invasão e o medo do hospital ser totalmente ocupado por doentes mentais. Passado este primeiro momento, a ocupação mostrou-se benéfica, pois até então, o HCST, encontrava-se em completo abandono por parte da Secretaria de Estado da Saúde, e com a chegada dos novos pacientes, houve uma mudança positiva, pois passaram a vir novos técnicos e recursos materiais.

Inicialmente a UAT, era vinculada técnica e administrativamente ao HCST. No entanto esta vinculação não foi benéfica, em função de conflitos técnicos - administrativos, fazendo com que a equipe de funcionários e pacientes, em 1991, retornassem aos seus vínculos de origem (HCS).

\section{AS ATIVIDADES DESENVOLVIDAS NESTES 10 ANOS}

A UAT contava inicialmente com um grupo de 14 pacientes e chegou à sua capacidade máxima com 50 pacientes. Este grupo passou a desenvolver atividades em várias áreas. A atividade principal sempre foi centralizada na agricultura, capina e jardinagem. O objetivo desta, previa um retorno econômico para os pacientes. Estes recebiam um salário simbólico enviado mensalmente pela Secretaria de Saúde, de acordo com sua produtividade e freqüência. $\mathrm{Na}$ mudança de governo, foi cancelado este pagamento e os técnicos e pacientes passaram a buscar recursos em outras fontes.

Em função das adversidades do tempo sobre a agricultura, do envelhecimento dos pacientes e do pouco assessoramento agricola, houve a necessidade de diversificaçăo das atividades. Os pacientes passaram a trabalhar com criação de aves e suinos de forma doméstica, de acordo com as vivências dos próprios pacientes e dos funcionários Foi permitido também, que os pacientes tivessem suas próprias atividades, desde que estas năo interferissem na rotina da unidade e não ferissem principios administrativos. Um dos pacientes passou a engraxar calçados na comunidade, outros foram contratados para serviços externos e um outro resolveu criar galos e comercializa-los, etc.

A reciclagem do lixo foi outra atividade desenvolvida pelos pacientes. Aproveitando o hábito de um dos pacientes de guardar o lixo em seu próprio quarto, foi estabelecido com este, um local adequado para o armazenamento do lixo, ao mesmo tempo, que era orientado que tipo 
de lixo deveria ser guardado. Este trabalho resultou na seleção e reciclagem do lixo, que passou a integrar uma das atividades da unidade ( reciclagem de papel, venda de ferro velho, papele papelão) e ainda, fez com que este paciente, transformasse um hábito mórbido, numa atividade produtiva e saudável.

Diante das doaçöes de roupas que a UAT vinha recebendo, vimos a necessidade de criar um local destinado ao recolhimento e distribuição destas, bem como de outras doaçōes.. Este local passou a denominar-se "bazar". Atualmente, este gera uma verba que tem possibilitado à equipe, comprar cigarros, complementos do vestuário, presentes de aniversário, realizar pagamento mensal dos pacientes, realizar passeios e até compra de medicamentos em falta. Importante destacar o trabalho da Terapia Ocupacional juntamente com o da enfermagem, no sentido de criar e manter as atividades da UAT, respeitando as competências e condições de cada paciente e de cada membro da equipe, ao mesmo tempo em que há uma mistura de papéis e uma ajuda mútua no desenvolvimento de todas as atividades.

\section{A AVALIAÇÃO DOS ASPECTOS DETERMINANTES DO PROJETO \\ A partir do que foi realizado podemos avaliar os aspectos norteadores:}

Dos resultados da comissäo para estudo da setorização do hospital, observamos que apesar da grande parcela de pacientes crônicos e asilares (55,7\%e 19,3\% respectivamente), a triagem tornou-se progressivamente mais dificil no sentido de encontrar pacientes que se enquadrassem nos critérios adotados. Mesmo ampliando-se estes critérios, a parcela de pacientes que permanecia no IPQ (antigo HCS), não tinha características condizentes na sua grande maioria para se beneficiar na UAT. As novas vagas que surgem na UAT, em geral são por óbitos e raras altas, existindo uma preocupação constante da equipe em buscar outros pacientes no IPQ, que se enquadre às propostas.

Quanto a história de superlotação do IPQ, observamos que a UAT representou muito mais uma perspectiva com nova ótica de tratamento para o paciente institucionalizado, do que propriamente, para a diminuição do número de pacientes internos. A solução da problemática é muito mais ampla, exigindo politicas de saúde mental junto a sociedade no sentido do retorno sócio - familiar o mais precoce possivel, de politicas de incentivo para que os hospitais psiquiátricos se tornem instituições de referência, a adoção de tratamentos modernos e mais eficientes, como os estipuladas na reforma psiquiátrica.

Quanto a história da ociosidade da planta física do HCST, viu- se que o projeto contribuiu significativamente. A curto prazo, a questăo da ocupação de uma parte da área física, foi fundamental para que este, não fosse destruido (desativado) gradativamente pelo desuso. A hanseniase, ao contrário do que se pensava inicialmente, ainda está longe de ser erradicada, fazendo com que o HCST, hoje não mais designado "colônia" e sim, somente Hospital Santa Teresa (HST), desempenhe um papel social e referencial para a sociedade catarinense. Embora todas diretrizes de tratamento do hanseniano, sejam ambulatoriais, estes pacientes, a exemplo dos doentes mentais, săo extremamente estigmatizados e por longos anos foram afastados da sociedade, tendo dificuldades de retorno sócio familiar, que vão desde o preconceito até as mutilações físicas decorrentes da doença.

Quanto às custas hospitalares, afirmamos que este tipo de internação barateia a permanência dos pacientes, pois proporciona aos mesmos uma independência relativa, fato que é estimulado pela equipe, além do que, o investimento por parte do Estado, é minimo e progressivamente menor, à medida em que o paciente é estimulado e passa a assumir algumas responsabilidades consigo mesmo.

Quanto à necessidade de implementação e pesquisa, acreditamos que este projeto, foi bastante importante, pois serviu como base para outros trabalhos, com pacientes crônicos 
no IPQ. Também porque a U.A.T., vem recebendo estudantes de vários cursos da área da saúde, assim como outros profissionais, servindo como "um modelo alternativo" no tratamento do paciente psiquiátrico crônico. Atualmente, o HST, oferece sua área ainda em desuso à Secretaria Estadual de Saúde para o desenvolvimento de outros projetos alternativos, tendo por base a UAT.

\section{A AVALIAÇĀO DOS OBJETIVOS QUE NORTEARAM A UNIDADE ANA TERESA}

Em relação ao paciente, a UAT, representou uma nova forma de viver, onde o doente mental passou a ser respeitado dentro de suas individualidades. Com açōes que vão desde o uso de suas roupas particulares, ter seus próprios pertences sobre seus cuidados, ter seu quarto, ser chamado pelo nome, ser chamado de "senhor" conforme a idade, receber seu beneficio e poder gastá-lo com o que lhe aprouver. Receber por trabalhos feitos, participar de rotinas diárias de vida, ter acesso a comunidade e fazer parte dela. Ter seus documentos consigo, votar, viver num ambiente aberto, sem grades, sem chaves e finalmente resgatar sua cidadania no seu sentido mais amplo, mesmo que esta se faça às custas da instituição. Observamos que muitos pacientes se acomodaram a esta nova situação à medida em que gradativamente sentiram-se aceitos e respeitados pelo grupo, à medida em que pouco a pouco conquistaram um novo espaço, onde no minimo recebem não somente alimentação e medicação, mas são respeitados como seres que pensam, sentem e amam.

Dos cento e dezessete (117) pacientes que em dez anos passaram pela unidade Ana Teresa, nove (09) foram à óbito, quarenta (40) pacientes retornaram definitivamente ao IPQ por não se adaptarem às propostas de trabalho, cinqüenta $(50)$ pacientes permaneceram e quatro (04) pacientes retornaram à sociedade e à familia sem nenhum retorno para o Hospital. Quatorze (14) pacientes restantes, foram transferidos por intercorrências clinicas ou psiquiátricas e retornaram para UAT. Dos cinqüenta $(50)$ pacientes que permaneceram, quatro $(04)$ fazem parte de um programa de retorno gradual e dezoito (18) têm familia e poderiam voltar para casa, no entanto, existe rejeição familiar e/ou abandono e muitas vezes constatamos que o paciente desistiu da familia e preferiu permanecer na UAT. Os vinte e oito (28) pacientes restantes, não têm familia, não têm condiçōes de subsistirem sós e são pacientes considerados não reabilitados, além de não terem para onde ir. Dos dezoitos (18) pacientes referidos acima, um (01) esteve fora do hospital por dois (2) anos e retornou manifestando sentimentos de medo e saudades do grupo, quatro (04) pacientes têm plena condiçōes de viverem sozinhos, mas preferem permanecer na U.A.T. onde referem sentirem-se protegidos e aceitos. Colocam claramente o medo de retornarem à sociedade.

Em relaçäo a equipe terapêutica, inicialmente composta por apenas uma (1) enfermeira e12 (doze) atendentes de enfermagem, foi integrado posteriormente por um médico. Somente em 1993, após muitos esforços, um terapeuta ocupacional passou a integrá-la. A equipe atualmente é formada por nove (9) auxiliares de enfermagem, uma (1) enfermeira, um (1) terapeuta ocupacional, um (1) técnico administrativo, dois (2) médicos, dois (2) serventes e cinqënta (50) pacientes ressaltamos que por trabalhar num sistema horizontalizado, incluimos os pacientes como parte da equipe). Quanto a formação técnica, vimos que mesmo sem o dominio do conhecimento necessário para o desenvolvimento do trabalho, a equipe buscava inicialmente realizar os objetivos de ressocialização e reabilitação, sob o aspecto do retorno sócio familiar. A transformação e aprendizado da equipe deu-se pelas experiências vivenciadas, por erros, acertos e persistência, e não pelos treinamentos que haviam sido propostos inicialmente no projeto e não aconteceram. $\mathrm{O}$ aprendizado foi construido através de frustraçōes, com os sucessos e o medo do retorno à situação anterior. No contato diário com os pacientes, a equipe identificava o valor que davam a nova forma de viverem e de estarem neste ambiente, o que fez com que a equipe repensasse muitas vezes, nos objetivos e propostas da Unidade Ana Teresa. 
A busca do objetivo principal do projeto, ou seja, o retorno à sociedade, era uma constante. Existia uma angústia latente ao percebermos no dia a dia o quanto isto era dificil de acontecer. Quando entendemos e aceitamos, que a U.A.T. era muito mais um asilo de doentes mentais crônicos do que um passo para o retorno do doente à familia e à sociedade, quando consideramos que a ressocializaçăo e reabilitação poderiam ser alcançadas, mesmo que permanecessem institucionalizados, pudemos refazer nossos objetivos e avançar mais ainda no processo de restauraçăo da cidadania destes pacientes.

Em relação à instituição, a UAT representou muito mais uma nova abordagem no tratamento do paciente crônico institucionalizado do que a diminuição significativa de internos. $O I P Q$, incentivado pelas novas diretrizes e bases de assistência à saúde mental, redefiniu suas propostas de trabalho e hoje possui 650 pacientes, sendo ainda a sua grande maioria composta de pacientes crônicos, em torno de 455. A UAT foi pioneira na proposta de um trabalho alternativo para o doente mental crônico, sendo seguido de outros trabalhos como a Unidade de Gestăo Participativa (UGP), a Pensão protegida para mulheres e atualmente o Centro de Convivência, onde todos os pacientes crônicos e asilares de ambos os sexos, ocupam uma área comum, com uma proposta mais comunitária. A UAT, faz parte deste Centro de Convivência ,embora localizado em outra área física.

\section{A AVALIAÇÃO DOS REQUISITOS ADOTADOS PARA A TRIAGEM}

Dos critérios adotados para o ingresso na UAT, foi mantido os aspectos relacionados a patologia prioritariamente esquizofrênica, sendo que cada caso é avaliado pela equipe técnica (médico, enfermeira e terapeuta ocupacional), e levado à equipe de funcionários e pacientes. As demais psicoses năo săo de fato excluidas, bem como os deficientes mentais moderados. Os pacientes com acentuados riscos săo observados e transferidos, caso representem efetivamente algum perigo para si próprio ou para o grupo.

Em muitos casos, observamos que muitos pacientes que apresentavam inúmeras fugas no IPQ, quando transferidos para a UAT, não mais fugiam, provavelmente pela possibilidade de saidas autorizadas, visitas regulares à família e ausência total de muros, grades e portas chaveadas.

A proposta de trabalhar somente com pacientes do sexo masculino se manteve, devido ao fato desse ser o maior contigente no IPQ e também porque um outro grupo de técnicos partiu para trabalhar com as mulheres, com propostas inovadoras como já citamos anteriormente.

O critério de procedência rural não foi seguido, pois viu-se que a população catarinense além de trabalhar na agricultura, participa de uma economia bastante diversificada, que vai desde a pesca, a mineraçăo, à indústria textil, fato que foi também evidenciado na populaçăo internada e a ser selecionada no IPQ.

A quantidade e o tipo de medicação que cada paciente fazia uso não representou em nenhum momento, obstáculos para seu ingresso na UAT. Ả medida em que seus sintomas produtivos diminuiam, que a afetividade melhorava e que outros aspectos sadios de sua personalidade eram resgatados, fazia-se uma diminuiçăo gradativa do uso de medicação. Os pacientes passaram a ter conhecimento e critica sobre a necessidade da medicação, o que possibilita estabelecer acordo sobre o uso de medicamentos, com o compromisso dos mesmo. Dos cinqënta (50) pacientes internados atualmente na UAT, quatro (4), năo utilizam medicaçăo psiquiátrica, doze (12), utilizam somente um tipo de medicação, vinte e dois (22), recebem dois tipos de medicaçăo e finalmente, doze (12) pacientes, utilizam mais de três medicaçōes psiquiátricas. Exeto em situaçōes de surto, as doses são gradativamente menor.

Quanto ao critério adotado, de que o paciente deveria ter condições clinicas compativeis 
com a atividade agricola, não foi um fator decisivo, pois as atividades passaram a ser diversificadas levando-se em conta à condiçőes fisicas, habilidades individuais, culturas e necessidades da unidade.

\section{CONCLUSÖES}

Passado dez anos da criação da Unidade Ana Teresa, podemos afirmar sem sombra de dúvidas, que vivemos uma experiência rica com pessoas antes marginalizadas, estigmatizadas, internadas em um macro hospital psiquiátrico estatal, sem perspectivas, e dentro de uma rotina mecânica, monótona, repetitiva, sem nenhuma ação que as tirasse da estagnação, ao contrário, que conseguia a cada dia que passava, mantê-las mais longe da sociedade, distanciando-as da vida, das pessoas, das coisas e do mundo real.

A Unidade Ana Teresa nasceu com a proposta terapêutica de reabilitaçăo bio-psicosocial e profissional. Quando idealizamos este objetivo, entendiamos que a reabilitação do paciente esquizofrênico crônico seria obtida, se todos esses aspectos fossem alcançados e năo tínhamos a noção exata da complexidade que isto representava. Estes dez anos de trabalho junto a esta clientela, nos forneceu uma série de ensinamentos e subsidios que nos fez repensar muitas vezes no verdadeiro papel que desempenhávamos, no futuro dessas pessoas e no caminho que deveriamos seguir, pois a cada dia, nos deparávamos com toda a ordem de dificuldades na busca de nossos objetivos

Construimos um ambiente terapêutico, devolvemos a maioria dos pacientes, sua identidade, possibilitamos que desenvolvessem suas potencialidades e habilidades, respeitamos sua privacidade, enfim, tentamos devolver à eles, o que o Estado, a instituição, a familia, e a sociedade lhes privou, nos longos anos de internação.

Porém, na maioria das vezes, na proporção em que a "ambientoterapia" tornou-se o maior enfoque da unidade, e que vários aspectos de resgate à cidadania foram paulatinamente conquistados por grande parte dos pacientes, os anseios de retornarem à familia e à sociedade tăo largamente colocados em outrora, foram substituidos pela verbalização do "querer permanecer".

Segundo Skinner (1979), "um ambiente terapêutico não acontece, ele precisa ser construido sistematicamente e reconstruido diariamente". Este esforço cria por si só uma atmosfera visto que provoca o crescimento tanto da equipe como dos pacientes. A reabilitação é tanto um método de tratamento quanto uma filosofia. Como método de tratamento é uma estrutura cientifica do meio ambiente, de forma a efetuar mudanças e melhorar a saúde e o funcionamento psicológico do individuo. Enquanto filosofia, é uma crença no valor da recuperação da livre expressão e no processo grupal como forma da proposta terapêutica.

Sob esta ótica, consideramos ter alcançado o objetivo de reabilitação, mesmo que esta se faça, as custas da instituição e que dela dependa para manter-se.

Acreditamos que os longos anos de internação sob as condiçōes mais desfavoráveis por que passaram, marcaram definitivamente suas vidas, institucionalizando-os, muitas vezes, de forma definitiva, mesmo que considerados reabilitados. Nos arriscamos ainda a fazer reflexões, do tipo: "talvez fosse necessário o dobro do tempo de internação, num processo intermediário entre a instituição e a sociedade, para que os pacientes se adaptassem ao mundo externo $e$ pudessem gozar na integra o que a sociedade oferece".

Consideramos que a passagem de uma estrutura para outra, bem distante da anterior, deverá passar por etapas intermediárias que visem a preparação adequada para um novo ambiente.

Acreditamos que, a esquizofrenia e outras doenças mentais tem seu diagnóstico piorado mais por contingências econômicas, sociais, e familiares, do que pelo próprio curso patológico, o que lhe confere uma pobreza prognostica. A problemática do doente mental é muito ampla 
e envolve questöes sociais, econômicas e culturais.

Apesar de uma pequena parcela dos doentes internados no atual IPQ, terem sido beneficiados com o trabalho realizado na Unidade Ana Teresa, consideramos que este, foi muito significativo, pois possibilitou à estes pacientes, o resgate de suas cidadanias.

Finalmente gostariamos de ressaltar que unidades deste tipo, podem vir a ser o primeiro passo para a desinstitucionalização do doente mental crônico com longos anos de internação. Nos preocupa a questão da desintitucionalização com o progressivo fechamento dos hospitais psiquiátricos conforme prevê as reforma psiquiátrica, se esta vier a ser instaurada como um dever do Estado e da Instituição, e não como um direito do paciente.

ABSTRACT: This project shows a new way of treatment for chronical and sheltered patients, to which the main objective is to offer a quality of life that allows them to be patients with personality, and citizens with all their potentialities.

KEYWORDS: psychiatric hospital, mental ill, nursing.

RESUMEN: Se trata de un proyecto que presenta un nuevo abordaje en el tratamiento destinado a pacientes siquiátricos crónicos e internados, cuyo objetivo principal es ofrecerles una condición de vida que les permita dejar de ser pacientes excluidos e impersonales para tornarse ciudadanos con total potencial.

PALAVRAS LLAVE: hospital siquiátrico, enfermo mental, enfermeria.

\section{REFERÊNCIAS BIBLIOGRÁFICAS}

AGUIAR, Maria Geralda Gomes. Movimentos de saúde mental: trajetória e futuro .In: CONGRESSO BRASILEIRO DE ENFERMAGEM, 47., 1995.Anais... Goiânia: ed. da UFG, 1996. 273 p.

ALBUQUERQUE, Manoel et al. Contribuiçōes da Psicanálise ao Instituto Psiquiátrico Forense. Revista de Psiquiatria Dinámica, v. 7 , n. 2, jun. 1967.

BEZERRA JUNIOR, Benilton. De Médico, de louco e de todo mundo um pouco: Campo Psiquiátrico no Brasil dos anos 80. In: GUIMARÄES, Reinaldo; TAVARES, Ricardo (Org). Saúde e Sociedade no Brasil dos anos 80. Rio de Janeiro: Relume-Dumará, 1994, p. 171 a 191

BRUM, Antonio Mainiere; VALENZUELA, Maria Cristina Illan. Fundamentos Teóricos de Reabilitação em Psiquiatria: Centro Agricola de Reabilitaçäo. Porto Alegre,1983.mimeogr.

FOUCAULT, Michel. História da Loucura. 4. ed. São Paulo: Perspectiva, 1995. 560 p. HCS - ARQUIVOS.O Centro de Reabilitaçāo Agricola (C.R.A). São José, 1986. mimeogr.

MOFFAT, A. Psicoterapia del Oprimido. Buenos Aires: Libreria Ecro SRL, 1975. 279 p. SKINNER, Katryn et al. The Terapeutic milieu: making it work. Journal Psychiatric Nors, v. 17, n. 8 , p. $38-44$, ago. 1979 . 